\title{
Cardiopulmonary bypass flow rate: A risk factor for hyperlactatemia after surgical repair of secundum atrial septal defect in children
}

\author{
Boban P. Abraham, MD ${ }^{\mathrm{a}, \mathrm{f}}$ Parthak Prodhan, MBBS, ${ }^{\mathrm{a}, \mathrm{b}, \mathrm{f}}$ Robert D. B. Jaquiss, MD, ${ }^{\mathrm{c}, \mathrm{f}}$ \\ Adnan T. Bhutta, MD, ${ }^{\mathrm{a}, \mathrm{b}, \mathrm{f}}$ Jeffrey M. Gossett, MS, ${ }^{\mathrm{d}, \mathrm{f}}$ Michiaki Imamura, MD, PhD,, ,f \\ Charles E. Johnson, RN, CCP, ${ }^{\mathrm{c}, \mathrm{f}}$ Michael L. Schmitz, MD, ${ }^{\mathrm{a}, \mathrm{c}, \mathrm{e}, \mathrm{f}}$ William R. Morrow, MD, ${ }^{\mathrm{a}, \mathrm{b}, \mathrm{f}}$ and \\ Umesh Dyamenahalli, MD ${ }^{\mathrm{a}, \mathrm{b}, \mathrm{f}}$
}

\begin{abstract}
Objective: Early postoperative hyperlactatemia is seen in some children after surgical repair of secundum atrial septal defect despite apparently normal cardiac output. The objective of the study was to investigate the intraoperative risk factors for hyperlactatemia in patients undergoing atrial septal defect repair.

Methods and Results: A retrospective review of 68 consecutive patients who underwent isolated atrial septal defect repair at Arkansas Children's Hospital between January 2001 and March 2006 was performed. Perioperative factors in the high lactate group (lactate $>3 \mathrm{mmol} / \mathrm{L}, \mathrm{n}=26$ ) were compared with those in the low lactate group $(n=42)$. Early hyperlactatemia was seen in $38 \%$ of the cohort. The high lactate group showed significantly lower weight-indexed cardiopulmonary bypass flow rate $\left(101 \pm 6.5 \mathrm{~mL} / \mathrm{kg}^{-1} / \mathrm{min}^{-1} \mathrm{vs} 131 \pm 6.0 \mathrm{~mL} / \mathrm{kg}^{-1} / \mathrm{min}^{-1}\right.$, $P=.0013$ ), oxygen delivery during cardiopulmonary bypass (mean $12.7 \pm 0.7 \mathrm{~mL} / \mathrm{kg}^{-1} / \mathrm{min}^{-1} \mathrm{vs} 17.0 \pm 1 \mathrm{~mL} /$ $\left.\mathrm{kg}^{-1} / \mathrm{min}^{-1}, P=.0009\right)$, and higher postoperative glucose $(191 \pm 8.6 \mathrm{mg} / \mathrm{dL}$ vs $151 \pm 5.4 \mathrm{mg} / \mathrm{dL}, P=.003)$ compared with the LL group. Multivariate logistic regression analysis showed that weight-indexed cardiopulmonary bypass flow rate $(P=.007)$ and average mean arterial blood pressure during cardiopulmonary bypass $(P=.009)$ were independent risk factors for postoperative hyperlactatemia. Cardiopulmonary bypass flow rate less than 100 $\mathrm{mL} / \mathrm{kg}^{-1} / \mathrm{min}^{-1}$ was associated with an odds ratio of 7.67 (95\% confidence interval, $1.28-45.86 ; P=.026$ ) for postoperative hyperlactatemia.
\end{abstract}

Conclusion: Lower weight-indexed cardiopulmonary bypass flow rate is an independent risk factor for early postoperative hyperlactatemia in children after atrial septal defect repair. (J Thorac Cardiovasc Surg 2010; 139:170-3)

Hyperlactatemia during and after cardiopulmonary bypass (CPB) has been linked to increased morbidity and mortality in children undergoing surgical repair of complex congenital heart diseases. ${ }^{1-3}$ Hyperlactatemia, however, is seen in some children who have undergone repair of atrial septal defect (ASD) despite evidence of good cardiac output. The significance of this finding and perioperative risk factors predictive of early postoperative hyperlactatemia in these children are unknown. We hypothesized that early hyperlactatemia in children undergoing uncomplicated ASD repair was secondary to intraoperative factors and not associated with measurable immediate adverse effects.

\section{MATERIALS AND METHODS}

\section{Study Design}

After institutional review board approval, a retrospective review of all consecutive patients who underwent surgical repair of isolated secundum ASD at

From the Department of Pediatrics, ${ }^{\mathrm{a}}$ Section of Pediatric Cardiology, ${ }^{\mathrm{b}}$ Section of Pediatric Cardiothoracic Surgery, ${ }^{\mathrm{c}}$ Department of Biostatistics, ${ }^{\mathrm{d}}$ Section of Pediatric Cardiothoracic Anesthesia, ${ }^{\mathrm{e}}$ University of Arkansas for Medical Sciences, College of Medicine, Arkansas, and Arkansas Children's Hospital, ${ }^{\mathrm{f}}$ Little Rock, Ark.

Received for publication Dec 23, 2008; revisions received April 2, 2009; accepted for publication April 22, 2009.

Address for reprints: Umesh Dyamenahalli, MD, 1 Children's Way, 512-3, Little Rock, AR 72202 (E-mail: Dyamenahalliumesh@uams.edu).

$0022-5223 / \$ 36.00$

Copyright (c) 2010 by The American Association for Thoracic Surgery doi:10.1016/j.jtcvs.2009.04.060
University of Arkansas for Medical Sciences between January 2001 and March 2006 was performed.

\section{Patient Population}

All patients aged less than 21 years who underwent surgical repair of ASD were included. We excluded all children who underwent repair of other additional congenital heart defects. For this study, we defined hyperlactatemia as arterial blood lactate level greater than $3 \mathrm{mmol} / \mathrm{L}$ and early postoperative period as the first 12 hours after admission to the intensive care unit. The study cohort was divided into 2 groups based on their highest measured blood lactate level during the first 12 postoperative hours. Those with blood lactate levels $3 \mathrm{mmol} / \mathrm{L}$ or less were designated as the low lactate (LL) group, and those with blood lactate levels greater than $3 \mathrm{mmol} / \mathrm{L}$ were designated as the high lactate (HL) group.

\section{Anesthetic, Cardiopulmonary Bypass, and Surgical Techniques}

Anesthesia was induced and maintained using inhaled and intravenous anesthetics (nitrous oxide and either sevoflurane or isoflurane and fentanyl \pm midazolam) along with non-depolarizing muscle relaxants. Pre-CPB, patients intravenously received methylprednisolone $(20 \mathrm{mg} / \mathrm{kg}$ until 2002) and dexamethasone $(0.5 \mathrm{mg} / \mathrm{kg}$ up to a maximum of $10 \mathrm{mg}$; after 2002), as per institutional standardized CPB protocol. The patients who received dexamethasone were also given the same dose orally the night before surgery. All defects were repaired via median sternotomy, and all repairs were accomplished with pericardial patches.

A Cobe-Stockert S3 heart lung machine (Sorin Group USA, Arvada, Colo) was used for CPB. For children weighing less than $20 \mathrm{~kg}$, a roller pump was used, whereas a centrifugal pump was used for those weighing 


\section{Abbreviations and Acronyms \\ $\mathrm{ASD}=$ atrial septal defect \\ $\mathrm{CPB}=$ cardiopulmonary bypass \\ $\mathrm{HL}=$ high lactate (group) \\ $\mathrm{LL}=$ low lactate (group)}

more than $20 \mathrm{~kg}$. A Terumo RX05RE oxygenator (Terumo Cardiovascular Systems Corporation, Ann Arbor, Mich) was used for children weighing less than $15 \mathrm{~kg}$, and an RX15RE oxygenator was used for those weighing more than $15 \mathrm{~kg}$. Cooling during CPB was passive, with active rewarming toward the end of the procedure. During CPB, the target flow rate was determined on the basis of body surface area and adjusted to maintain mixed venous oxygen saturation greater than $75 \%$, as assessed by a continuous inline oximetry probe in the venous return line of the CPB circuit.

\section{Data Collection}

We identified patients from our cardiovascular surgical registry and retrospectively reviewed the hospital charts and perfusion records of the selected patients.

\section{Statistical Analysis}

The study cohort was divided into 2 groups based on their highest measured blood lactate level during the first 12 postoperative hours. Those with blood lactate level $3 \mathrm{mmol} / \mathrm{L}$ or less were designated as the $\mathrm{LL}$ group, and those with blood lactate level greater than $3 \mathrm{mmol} / \mathrm{L}$ were designated as the $\mathrm{HL}$ group. Risk factors for hyperlactatemia were screened using chi-square tests of association for categoric variables, $t$ tests for approximately normally distributed continuous variables, and Wilcoxon rank-sum tests for non-normally distributed variables. Candidate risk factors and demographic factors considered in the stepwise logistic analysis included weight-indexed CPB flow, crossclamp and CPB time, time to rewarm, lowest temperature during $\mathrm{CPB}$, lowest intraoperative hematocrit, average mean arterial blood pressure during $\mathrm{CPB}$, maximum intraoperative glucose, and gender. Oxygen delivery was calculated using the formula: pump flow $\left(\mathrm{mL} / \mathrm{kg}^{-1} / \mathrm{min}^{-1}\right)$ times oxygen content of the blood (hemoglobin $\times \mathrm{S}_{\mathrm{AO}_{2}} \times 1.36+0.003 \times \mathrm{PAO}_{2}$ )/100). A bootstrap analysis was performed (using the SWBOOT function in Stata 10 [StataCorp LP, College Station, Tex]) to confirm robustness of the stepwise logistic regression analysis. Data analysis was performed using SAS V 9.1 (SAS Institute Inc, Carey, NC) and Stata 10.

\section{RESULTS}

Sixty-eight patients fulfilled our inclusion criteria and were enrolled in the study. The demographic characteristics of the patients are summarized in Table 1 . The median age of the entire cohort was 55 months (range 5-201 months). Postoperative hyperlactatemia was seen in 26 of 68 study patients $(38 \%)$. None of the patients had renal or hepatic dysfunction in the perioperative period.

The characteristics of the 2 groups during CPB are summarized in Table 1. Average body weight-indexed CPB flow was significantly lower in the HL group $(101 \pm 6.5$ $\mathrm{mL} / \mathrm{kg}^{-1} / \mathrm{min}^{-1}$ [mean \pm standard error of the mean] in $\mathrm{HL}$ vs $131 \pm 6.0 \mathrm{~mL} / \mathrm{kg}^{-1} / \mathrm{min}^{-1}$ in LL, $P=.001$ ). The Pearson correlation between body weight and body surface area in our cohort was 0.9917. Oxygen delivery during CPB was significantly lower in the HL group $\left(12.7 \pm 0.7 \mathrm{~mL} / \mathrm{kg}^{-1} /\right.$ $\mathrm{min}^{-1}$ in HL vs $17.0 \pm 1 \mathrm{~mL} / \mathrm{kg}^{-1} / \mathrm{min}^{-1}$ in LL, $\left.P=.001\right)$ be-
TABLE 1. Demographics and operative characteristics

\begin{tabular}{|c|c|c|c|}
\hline Variables & LL group & HL group & $P$ value \\
\hline Preoperative variables & Mean \pm SD & Mean \pm SD & \\
\hline Age (mo) & $67.5 \pm 53$ & $99 \pm 55$ & .025 \\
\hline Weight (kg) & $20.5 \pm 14$ & $33 \pm 20$ & .009 \\
\hline Height $(\mathrm{cm})$ & $105.5 \pm 30$ & $129 \pm 31$ & .003 \\
\hline Body mass index & $16.5 \pm 2.3$ & $17.6 \pm 3.7$ & .183 \\
\hline Body surface area & $0.76 \pm 0.37$ & $1.07 \pm 0.46$ & .004 \\
\hline Proportion of boys $(\%)$ & 14.3 & 38.5 & .02 \\
\hline $\begin{array}{l}\text { Preoperative diuretic/ } \\
\text { vasodilator treatment }(\%)\end{array}$ & 9.5 & 3.8 & .625 \\
\hline $\begin{array}{l}\text { ASD associated with } \\
\text { syndromes }(\%)\end{array}$ & 12 & 0 & \\
\hline ASD size $(\mathrm{cm})$ & $1.52 \pm 0.73$ & $1.26 \pm 0.86$ & .24 \\
\hline \multicolumn{4}{|l|}{ Intra/postoperative variables } \\
\hline $\begin{array}{l}\text { Postoperative moderate to } \\
\text { severe RV dilation (\%) }\end{array}$ & 67 & 65 & \\
\hline Bypass time (min) & $34.6 \pm 10.3$ & $36.5 \pm 11.2$ & .48 \\
\hline Crossclamp time (min) & $12.7 \pm 6.2$ & $13.4 \pm 6.3$ & .65 \\
\hline $\begin{array}{l}\text { Mixed venous oxygen } \\
\text { saturation }(\%)\end{array}$ & $74.9 \pm 6.7$ & $73.0 \pm 6.0$ & .26 \\
\hline Pump flow (mL/min $\left.{ }^{-1} / \mathrm{kg}^{-1}\right)$ & $131 \pm 38.2$ & $101 \pm 33.3$ & .001 \\
\hline $\begin{array}{l}\text { Intraoperative mean arterial } \\
\text { blood pressure }(\mathrm{mm} \mathrm{Hg})\end{array}$ & $49.2 \pm 6.1$ & $47.9 \pm 5.6$ & .38 \\
\hline $\begin{array}{l}\text { Lowest intraoperative core } \\
\text { temperature }(\mathrm{C})\end{array}$ & $32.3 \pm 1.7$ & $32.3 \pm 1.8$ & .87 \\
\hline Rewarming time (min) & $20.5 \pm 5.7$ & $19.6 \pm 4.6$ & .53 \\
\hline Duration of surgery (min) & $132.6 \pm 24.3$ & $133.4 \pm 24.7$ & .89 \\
\hline Duration of anesthesia (min) & $211.7 \pm 43.3$ & $211.2 \pm 26.4$ & .95 \\
\hline $\begin{array}{l}\text { Average intraoperative } \\
\text { hemoglobin }(\mathrm{g} / \mathrm{dL})\end{array}$ & $9.0 \pm 1.5$ & $8.9 \pm 1.2$ & .73 \\
\hline $\begin{array}{l}\text { Intraoperative oxygen content } \\
\quad(\mathrm{mL} / \mathrm{mL})\end{array}$ & $0.13 \pm 0.02$ & $0.13 \pm 0.02$ & .92 \\
\hline $\begin{array}{l}\text { Intraoperative oxygen } \\
\text { delivery }\left(\mathrm{mL} / \mathrm{min}^{-1} / \mathrm{kg}^{-1}\right)\end{array}$ & $17.0 \pm 6.2$ & $12.7 \pm 3.6$ & .001 \\
\hline
\end{tabular}

cause of differences in the $\mathrm{CPB}$ flow rate. A strong correlation between $\mathrm{CPB}$ flow and oxygen delivery (correlation 0.9 , $\mathrm{r}^{2}=0.81, P=.001$ ) was observed (Figure 1).

Base deficit (LL vs $\mathrm{HL}-3.17 \pm 2.1$ vs $-4.39 \pm 2.5$, $P=.033)$, maximum anion gap (11.6 \pm 3.3 vs $13.4 \pm 2.7$, $P=.023)$, and bicarbonate levels ( $23.8 \pm 1.5$ vs $22.8 \pm 2.3$, $P=.039)$ were significantly different between the 2 groups in the first 12 postoperative hours. Intraoperative and postoperative hematocrit, intraoperative lactate, and the use of postoperative inotropic medications were the same in the 2 groups. Postoperative hyperlactatemia significantly correlated with CPB flow rate (coefficient $=-0.35, \mathrm{r}^{2}=0.12, P=.004$ ) and consequently oxygen delivery (coefficient $=-0.31, \mathrm{r}^{2}=$ $0.08, P=.013$ ) (Figure 2). Multivariate logistic regression showed that the weight-indexed CPB flow rate was an independent predictor of postoperative high lactate $(P=.007)$. A CPB flow less than $100 \mathrm{~mL} / \mathrm{kg}^{-1} / \mathrm{min}^{-1}$ was associated with an odds ratio of 7.67 (95\% confidence interval 1.28 $45.86, P=.026)$ for postoperative hyperlactatemia. An increase in pump flow of $1 \mathrm{~mL} / \mathrm{kg}^{-1} / \mathrm{min}^{-1}$ decreased the odds 


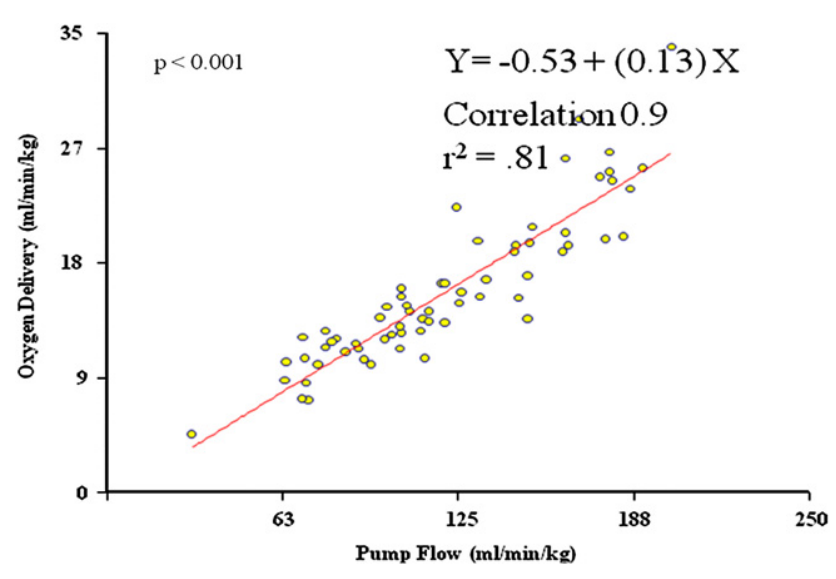

FIGURE 1. Oxygen delivery is significantly correlated with pump flow, leading to the assumption that oxygen delivery is dependent on pump flow.

ratio of hyperlactatemia $(>3 \mathrm{mmol} / \mathrm{L})$ by a factor of $0.959(P<$ .003). Higher mean arterial blood pressure was associated with reduced odds of high lactate. An increase in intraoperative mean arterial blood pressure by $1 \mathrm{~mm} \mathrm{Hg}$, with CPB flow fixed, decreased the odds ratio of hyperlactatemia $(>3$ $\mathrm{mmol} / \mathrm{L})$ by a factor of $0.8343(P<.009)$.

Serum glucose levels were similar between groups during surgery but were significantly elevated in the postoperative period in the HL group compared with the LL group (Table 2). None of the patients in the LL group received insulin in the postoperative period compared with 4 of 26 patients $(15.4 \%)$ in the HL group. Postoperative lactate and glucose levels were significantly correlated (coefficient $0.53, \mathrm{r}^{2}=0.28, P<.001$ ).

Postoperative hyperlactatemia was not associated with any measurable adverse outcomes in the immediate postoperative period, as measured by time to extubation (LL vs HL $7.2 \pm$ 4.7 hours vs $5.8 \pm 2.9$ hours, $P=.13$ ) and the length of inten- sive care unit ( $3.1 \pm 0.79$ days vs $2.7 \pm 0.72$ days, $P=.06)$ and hospital stay $(4.8 \pm 2.1$ days vs $4.1 \pm 0.69$ days, $P=.04)$.

\section{DISCUSSION}

This study demonstrated the following: (1) Low CPB flow rate and mean of mean blood pressure during $\mathrm{CPB}$ are independent risk factors for the development of early postoperative hyperlactatemia in children undergoing ASD repair. The decreased oxygen delivery seen in the HL group is attributable to the low CPB flow rate and not to the difference in oxygen content. (2) Postoperative hyperglycemia is linked to postoperative hyperlactatemia. (3) Hyperlactatemia is not associated with increased resource use in the immediate postoperative period.

Most studies investigating hyperlactatemia in children undergoing surgery have focused on complex congenital heart diseases. In these patients, the duration of CPB and circulatory arrest, nadir temperature, duration of cooling and rewarming, hematocrit during and after $\mathrm{CPB}$, and systemic inflammatory response to CPB are likely contributors to hyperlactatemia. ${ }^{1-4}$ Contrary to our study, these investigations have linked hyperlactatemia and adverse outcomes in patients undergoing surgery for Risk Adjustment for Congenital Heart Surgery category III or IV lesion and not with category I procedures such as ASD repair, in which patients maintain good cardiac output in the postoperative period. ${ }^{5}$ Because of the complex and confounding perioperative factors, such as cardiac output and organ dysfunction, intraoperative factors were not examined separately in these studies. The significance of our study is in the homogeneity and lack of medical complexity in the study population that helped us to focus on intraoperative variables.

In this study, the main intraoperative risk factor for early postoperative hyperlactemia was the $\mathrm{CPB}$ flow rate. $\mathrm{CPB}$

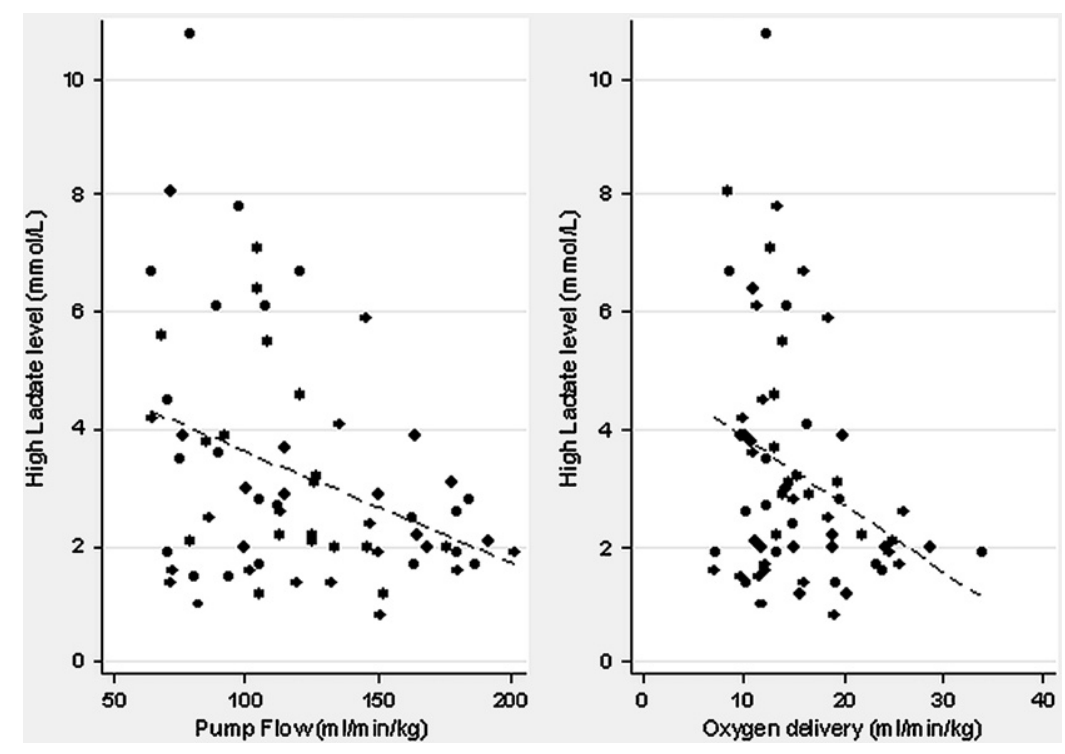

FIGURE 2. Hyperlactatemia is inversely related to pump flow and oxygen delivery. 
TABLE 2. Lactate and glucose levels

\begin{tabular}{lccc}
\hline & $\begin{array}{c}\text { LL group } \\
\text { Mean } \pm \text { SD }\end{array}$ & $\begin{array}{c}\text { HL group } \\
\text { Mean } \pm \text { SD }\end{array}$ & $\boldsymbol{P}$ value \\
\hline $\begin{array}{l}\text { Intraoperative lactate } \\
\quad(\mathrm{mmol} / \mathrm{L})\end{array}$ & $1.64 \pm 0.70$ & $1.94 \pm 0.74$ & .117 \\
$\begin{array}{l}\text { Lactate level at admission to } \\
\quad \text { ICU (mmol/L) }\end{array}$ & $1.47 \pm 0.43$ & $2 \pm 0.91$ & .009 \\
$\begin{array}{l}\text { Peak postoperative lactate } \\
\quad \text { level (mmol/L) }\end{array}$ & $1.98 \pm 0.55$ & $5.23 \pm 1.89$ & .0001 \\
$\begin{array}{l}\text { Time to peak lactate level in } \\
\text { the postoperative period (h) }\end{array}$ & $3.55 \pm 3.54$ & $5.57 \pm 2.82$ & .012 \\
$\begin{array}{l}\text { Intraoperative glucose levels } \\
\quad(\mathrm{mg} / \mathrm{dL})\end{array}$ & $183 \pm 66.7$ & $186 \pm 44.7$ & .83 \\
$\begin{array}{l}\text { Postoperative glucose levels } \\
\quad(\mathrm{mg} / \mathrm{dL})\end{array}$ & $151 \pm 35.2$ & $191 \pm 44$ & .0003 \\
\hline
\end{tabular}

$L L$, Low lactate; $H L$, high lactate; $S D$, standard deviation; $I C U$, intensive care unit.

flow rate and blood oxygen content are key determinants of oxygen delivery. ${ }^{6}$ The oxygen content is further dependent on hematocrit level, which if low during CPB is associated with poor outcome and increased lactate.

Despite similar hematocrit levels and targeted mixed venous oxygen saturation of more than $75 \%$ in both the groups, we speculate that differential hypoperfusion of some organs during CPB was the cause of postoperative hyperlactatemia. Interventions such as setting a higher target mixed venous saturations or use of vasodilators (sodium nitroprusside, milrinone, or phenoxybenzamine) may ameliorate this problem. In the observed group, the bigger children had a lower CPB flow rate (Figure 3); therefore, it is important to aim for higher mixed venous saturations and use vasodilators during the $\mathrm{CPB}$ to improve the overall tissue perfusion. This consideration may be particularly important in older, larger children.

Other factors affecting optimal CPB flow rate include cooling strategy (pH-stat vs alpha- stat) used during $\mathrm{CPB} .^{8}$ In surgeries using deep hypothermia $\left(15^{\circ} \mathrm{C}-18^{\circ} \mathrm{C}\right)$, low CPB flow rates less than $100 \mathrm{~mL} / \mathrm{kg}^{-1} / \mathrm{min}^{-1}$ are used. However, during ASD repairs relatively higher temperatures are maintained during bypass, which might require higher $\mathrm{CPB}$ flow rate to maintain adequate oxygen delivery.

A significant correlation between hyperglycemia and hyperlactatemia was observed in this study. This finding is similar to that found in other cardiac surgery studies. ${ }^{9,10}$ The presence of low CPB flow rate and the resulting stress likely induce release of counter-regulatory hormones and activation of cytokines causing hyperglycemia. Hyperlactatemia and hyperglycemia can worsen each other in a vicious cycle because anaerobic metabolism of excess glucose and production of lactate occurs via the Cori cycle., ${ }^{9,10}$

\section{Study Limitations}

This was a retrospective case-control study. Detailed analysis of the causes of hyperlactatemia, including pyruvatelactate ratio, was not possible from the existing data. We do not have postoperative mixed venous saturations to abso-

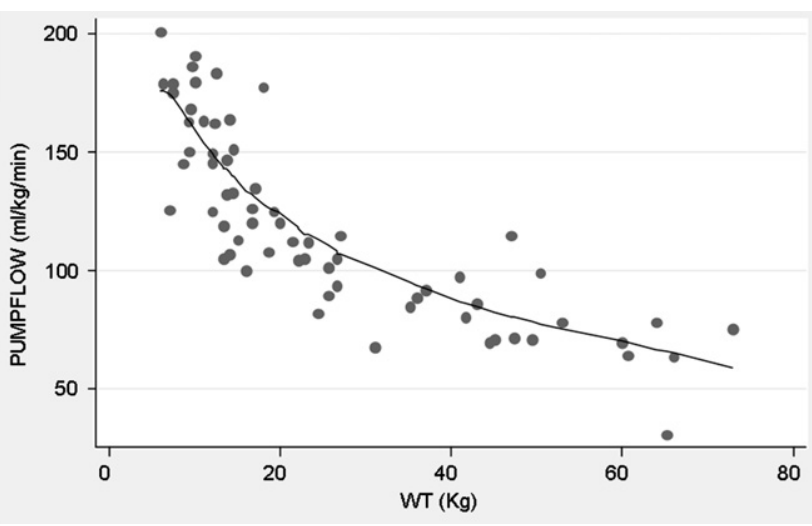

FIGURE 3. Pump flow rate $(\mathrm{mL} / \mathrm{min} / \mathrm{kg})$ decreases with increasing weight of the child.

lutely confirm the adequacy of postoperative cardiac output. We have no longer-term data to comment on the impact, if any, of hyperlactatemia on neurodevelopmental outcomes. ${ }^{11}$

\section{CONCLUSIONS}

Lower CPB flow rate is an independent risk factor for postoperative hyperlactatemia after surgical closure of secundum ASD, but it is not associated with increased resource use.

\section{References}

1. Hamamoto M, Uemura H, Imanaka H, Yagihara T. Relevance of the measurement of the concentration of lactate in the serum subsequent to the Fontan procedure in small children. Cardiol Young. 2006;16:275-80.

2. Cheung PY, Chui N, Joffe AR, Rebeyka IM, Robertson CMT. and the Western Canadian Complex Pediatric Therapies Project, Follow-up Group. Postoperative lactate concentrations predict the outcome of infants aged 6 weeks or less after intracardiac surgery: a cohort follow-up to 18 months. J Thorac Cardiovasc Surg. 2005; 130:837-43.

3. Munoz R, Laussen PC, Palacio G, Zienko L, Piercey G, Wessel DL. Changes in whole blood lactate levels during cardiopulmonary bypass for surgery for congenital cardiac disease: an early indicator of morbidity and Mortality. J Thorac Cardiovasc Surg. 2000;119:155-62.

4. Duke T, Butt W, South M, Karl TR. Early markers of major adverse events in children after cardiac operations. J Thorac Cardiovasc Surg. 1997;114:1042-52.

5. Jenkins KJ, Newburger JW, Lock JE, Davis RB, Coffman GA, Iezzoni LI. In-hospital mortality for surgical repair of congenital heart defects: preliminary observations of variation by hospital caseload. Pediatrics. 1995;95:323-30.

6. Ranucci M, Toffol BD, Isgrò G, Romitti F, Conti D, Vicentini M. Hyperlactatemia during cardiopulmonary bypass: determinants and impact on postoperative outcome. Critical Care. 2006;10:R167.

7. Jonas RA, Wypij D, Roth SJ, Bellinger DC, Visconti KJ, du Plessis AJ, et al. The influence of hemodilution on outcome after hypothermic cardiopulmonary bypass: results of a randomized trial in infants. J Thorac Cardiovasc Surg. 2003; 126:1765-74.

8. Anttila V, Hagino I, Zurakowski D, Iwata Y, Duebener L, Lidov HGW, et al. Specific bypass conditions determine safe minimum flow rate. Ann Thorac Surg. 2005;80:1460-7.

9. Chioléro RL, Revelly JP, Leverve X, Gersbach P, Cayeux MC, Berger MM, et al. Effects of cardiogenic shock on lactate and glucose metabolism after heart surgery. Crit Care Med. 2000;28:3784-91.

10. Nilsson F, Ekroth R, Milocco I, Nilsson NJ, Svensson S, Berglin E, et al. Splanchnic glucose balance and insulin resistance in the early postoperative phase of cardiac surgery. J Parenter Enteral Nutr. 1988;12:574-8.

11. Visconti KJ, Bichell DP, Jonas RA, Newburger JW, Bellinger DC. Developmental outcome after surgical versus interventional closure of secundum atrial septal defect in children. Circulation. 1999;100 [suppl II]:II-145-50. 